\title{
Correction to: Nonlinear Dielectric Response of Nanocomposites Based on Potassium Dihydrogen Phosphate
}

\author{
Alexey Milinskii ${ }^{1} \cdot$ Sergey Baryshnikov ${ }^{2} \cdot$ Vladimir Parfenov $^{3} \cdot$ Svetlana Kozlola $^{3} \cdot$ Nguyen Hoai Thuong $^{4,5}$
}

Published online: 12 April 2018

(c) The Korean Institute of Electrical and Electronic Material Engineers 2018

\section{Correction to: Transactions on Electrical and Electronic Materials https://doi.org/10.1007/s42341-018-0032-x}

The original version of this article unfortunately contained a mistake. The spelling of the fourth author's name "Svetlana Kozlola" was incorrect.

The original article has been corrected.

The original article can be found online at https://doi.org/10.1007/ s42341-018-0032-x.

Nguyen Hoai Thuong nguyenhoaithuong@tdt.edu.vn

1 Blagoveschensk State Pedagogical University, Blagoveshchensk, Russia 675000

2 Amur State University, Blagoveshchensk, Russia

3 Institute of Chemistry and Chemical Technology, Krasnoyarsk, Russia

4 Division of Computational Physics, Institute for Computational Science, Ton Duc Thang University, Ho Chi Minh City, Vietnam

5 Faculty of Electrical \& Electronics Engineering, Ton Duc Thang University, Ho Chi Minh City, Vietnam 